University of Nebraska - Lincoln

DigitalCommons@University of Nebraska - Lincoln

2006

\title{
Well-Defined Poly(4-vinylbenzocyclobutene): Synthesis by Living Anionic Polymerization and Characterization
}

Georgios Sakellariou

Durairaj Baskaran

Nikos Hadjichristidis

Jimmy W. Mays

Follow this and additional works at: https://digitalcommons.unl.edu/usdoepub

Part of the Bioresource and Agricultural Engineering Commons

Sakellariou, Georgios; Baskaran, Durairaj; Hadjichristidis, Nikos; and Mays, Jimmy W., "Well-Defined Poly(4-vinylbenzocyclobutene): Synthesis by Living Anionic Polymerization and Characterization" (2006). US Department of Energy Publications. 80.

https://digitalcommons.unl.edu/usdoepub/80

This Article is brought to you for free and open access by the U.S. Department of Energy at DigitalCommons@University of Nebraska - Lincoln. It has been accepted for inclusion in US Department of Energy Publications by an authorized administrator of DigitalCommons@University of Nebraska - Lincoln. 


\title{
Well-Defined Poly(4-vinylbenzocyclobutene): Synthesis by Living Anionic Polymerization and Characterization
}

\author{
Georgios Sakellariou, ${ }^{\dagger}$ Durairaj Baskaran, ${ }^{*, \sharp}$ Nikos Hadjichristidis, ${ }^{\S}$ and \\ Jimmy W. Mays*,;, \\ Department of Chemistry, University of Tennessee, 552 Buehler Hall, Knoxville, Tennessee 37996; \\ Chemical Sciences Division, Oak Ridge National Laboratory, Oak Ridge, Tennessee 37831; Department \\ of Chemistry, University of Athens, Panepistimiopolis-Zografou, 15771 Athens, Greece; and Polymer \\ Science and Engineering Division, National Chemical Laboratory, Pune 411 008, India
}

Received January 24, 2006; Revised Manuscript Received March 17, 2006

\begin{abstract}
Living anionic polymerization of 4-vinylbenzocylobutene was performed in benzene at room temperature using sec-butyllithium as the initiator. Results of the kinetic studies indicated the termination- and transfer-free nature of the polymerization. Homopolymers with predictable molecular weights and narrow molecular weight distributions were produced, excluding the interference of the cyclobutene rings during initiation and propagation. Thermogravimetric analysis of poly(4-vinylbenzocyclobutene) in air showed a small weight gain at $\sim 200{ }^{\circ} \mathrm{C}$, a rapid decomposition at $\sim 455^{\circ} \mathrm{C}$, and a gradual decomposition at $\sim 566^{\circ} \mathrm{C}$. This behavior was attributed to the formation of radicals from the pendent benzocyclobutene functionality through $o$-quinodimethane intermediates and simultaneous decomposition/cross-linking reactions at high temperature. The living nature of the polymerization was also examined via sequential copolymerization with butadiene to form diblock copolymers.
\end{abstract}

\section{Introduction}

Anionic polymerization of styrene and dienes proceeds without side reactions in nonpolar solvents. ${ }^{1,2}$ The living character of these polymerizations allows judicious manipulation of active chain ends, facilitating the synthesis of architecturally controlled homopolymers and copolymers, as well as allowing for the synthesis of end-functionalized polymers by reaction of macroanions with suitable electrophilic reagents. ${ }^{3-7}$ Welldefined polystyrene- and polydiene-containing multiblock, miktoarm star, regular comb, and centipede copolymers have been synthesized using anionic polymerization. ${ }^{8-13}$ These copolymers can self-assemble in solution and in bulk to form micelles, vesicles, and microphase-separated bulk morphologies with features on the nanoscale. ${ }^{14}$ The introduction of functional groups into monomers that do not interfere with the living polymerization mechanism, allowing for the synthesis of block copolymers and subsequently stabilizing the self-assembled nanostructures by cross-linking, is essential for developing novel nanomaterials. Early efforts in this area were reported by Liu ${ }^{15-17}$ and more recently by Hawker and co-workers. ${ }^{18}$

The presence of polar functional groups in styrene requires appropriate protection to avoid side reactions with the anionic initiator and the propagating active center. ${ }^{19-22}$ A number of styrene derivatives bearing protected functional groups have been polymerized through anionic polymerization. ${ }^{19}$ In general, the hydroxyl and amine groups in styrene are protected by tertbutyldimethylsilylane. ${ }^{23}$ Hirao and co-workers pioneered this strategy and showed that the para-substituted styrene undergoes anionic polymerization in a living manner. They prepared poly(para-substituted styrene)s with a variety of functional groups such as $-\mathrm{OH},-\mathrm{NH}_{2},-\mathrm{CHO},-\mathrm{COOH},-\mathrm{CH}_{2} \mathrm{CH}_{2} \mathrm{OH}$, etc. ${ }^{19}$ However, noninterfering alkyl- and aryl-substituted styrene

\footnotetext{
$\dagger$ University of Tennessee.

$\doteqdot$ National Chemical Laboratory.

$\S$ University of Athens.

\# Oak Ridge National Laboratory.

* Corresponding authors. E-mail: d.baskaran@ncl.res.in or jimmymays@ utk.edu.
}

undergo anionic polymerization without side reactions in hydrocarbon medium. ${ }^{24}$ Zhang and Ruckenstein showed that 4-(vinylphenyl)-1-butene undergoes anionic polymerization without affecting butene pendants. ${ }^{20}$

Cycloalkyl substituted styrenes, such as 4-vinylbenzocyclobutene (4-VBCB), ${ }^{25,26}$ have been synthesized by Endo ${ }^{27-29}$ and, more recently, by Hawker et al. ${ }^{30}$ and were used in radical and controlled atom transfer radical polymerization, respectively. The synthesis and the polymerization of $4-\mathrm{VBCB}$ using radical and anionic polymerization were first documented in the patent literature in 1987. ${ }^{25,26}$ Polymers and copolymers obtained from 4-vinylbenzocyclobutene contain pendant benzocyclobutene groups, which undergo radical cross-linking at $200{ }^{\circ} \mathrm{C} .{ }^{31,32} \mathrm{The}$ chemistry of 1,2-dihydrobenzocyclobutene (i.e., benzocyclobutene: $\mathrm{BCB}$ ) has been extensively studied and utilized as a synthetic intermediate, since $\mathrm{BCB}$ can be regarded as an equivalent of $o$-quinodimethane under thermal isomerization conditions. ${ }^{31}$ It readily undergoes Diels - Alder adduct formation with dienophiles quantitatively. ${ }^{33}$ Hawker and co-workers have elegantly exploited the thermally switchable cross-linking behavior of poly(4-vinylbenzocyclobutene) to synthesize polymeric nanoparticles through intramolecular cross-linking. ${ }^{30}$ The intermolecular cross-linking of benzocyclobutene groups in block copolymers has also been used in making various nanostructures, including cross-linked polymer brushes. ${ }^{18,32,34}$

In this context, the living anionic polymerization of $4-\mathrm{VBCB}$ is of significant interest for its potential to open a path to the synthesis of a host of block copolymer architectures, incorporating a cross-linking monomer (4-VBCB) and other monomers including butadiene and isoprene. Such materials show interesting morphologies in solution and in the solid state. ${ }^{9,14}$ Diblock copolymers containing benzocyclobutene pendants would yield benzocyclobutene-enriched microphases that can be used to synthesize nanoparticles, nanochannels and nanorods through thermal cross-linking.

In this paper, we describe the living anionic polymerization of 4-VBCB using sec-butyllithium as initiator in benzene at room temperature. The living nature of the polymerization is 


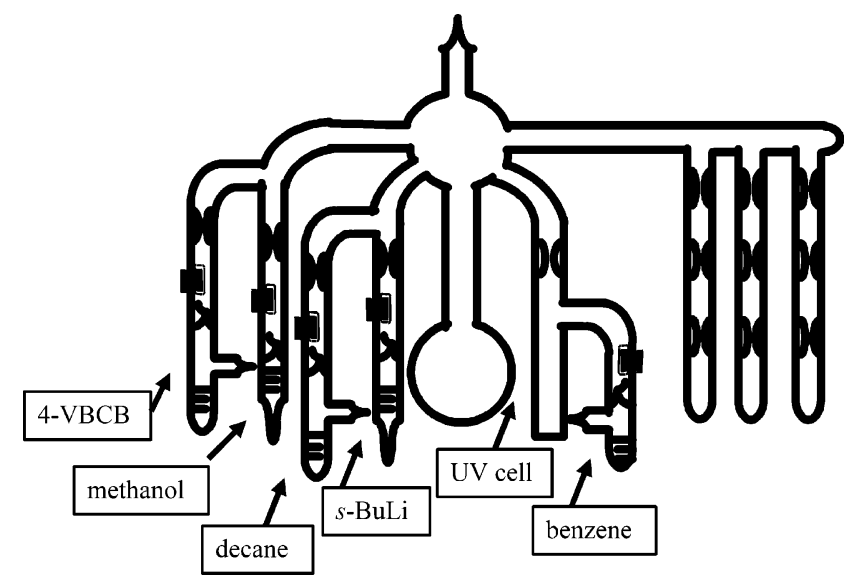

Figure 1. Polymerization reactor used for the kinetics and UV-vis measurements.

examined through kinetic measurements and diblock copolymer formation with butadiene. The cross-linking of poly(4-vinylbenzocyclobutene) was also studied in the solid state.

\section{Experimental Section}

Materials. All chemicals were purchased from Aldrich Chemical Co., except 4-bromobenzocyclobutene (97\%), which was generously donated by the Dow Chemical Company. Dibutylmagnesium (1 $\mathrm{M}$ in heptane), 1,2-dibromoethane (99\%), sodium (99\%, lumps in kerosene), potassium ( $98 \%$, chunks in mineral oil), calcium hydride $\left(\mathrm{CaH}_{2}\right)$, sodium hydroxide $(97 \%, \mathrm{NaOH}), \mathrm{Mg}$ turnings $(99.98 \%)$, methyltriphenylphosphonium bromide (98\%), ammonium chloride $(99.5 \%)$, sodium bicarbonate $(99.7 \%)$, and $n$-butyllithium (1.6 M in hexane) were used as received. Benzene was prepurified by stirring over concentrated sulfuric acid for a week, washing with an aqueous solution of $\mathrm{NaOH}$, and washing with water until neutral and finally dried over $\mathrm{CaCl}_{2}$. The prepurified benzene was stirred over $\mathrm{CaH}_{2}$ and degassed, before distilling into a flask containing a small amount of $n$-BuLi and styrene connected to a vacuum line. Tetrahydrofuran (THF) was stirred over $\mathrm{CaH}_{2}$ and degassed and stored in a vacuum line. THF was further distilled into a flask containing $\mathrm{Na} / \mathrm{K}(1: 3)$ alloy. The bright blue color develops after stirring for some time due to solvated electrons. Decane was purified by distilling from a small amount of $\mathrm{CaH}_{2}$ and further distilled from $n$-BuLi. Dimethylformamide (DMF) was distilled over $\mathrm{NaOH}$. Other solvents such as ethyl acetate, diethyl ether, and hexane were used as received. 4-Bromobenzocyclobutene was distilled under vacuum and stored under $\mathrm{N}_{2}$.

$s e c$-Butyllithium ( $s$-BuLi), synthesized by the reaction of secbutyl chloride and lithium metal, was used as the polymerization initiator. The concentration of $s$-BuLi was determined using standard styrene polymerization under a high vacuum and the measured number-average molecular weight of the obtained polystyrene at $100 \%$ conversion. 1,3-Butadiene was distilled from $\mathrm{CaH}_{2}$ over to a flask containing chunks of sodium metal and kept stirring for a few hours under vacuum at $-10^{\circ} \mathrm{C}$. Then, the required amount of 1,3-butadiene was distilled into glass ampules which was diluted by distilling $n$-hexane (twice a volume of diene) and sealed off. 4-Vinylbenzocyclobutene was synthesized from 4-carboxaldehydebenzocyclobutene as reported in the literature. ${ }^{30}$ The monomer was purified by distilling from $\mathrm{CaH}_{2}$ and from dibutylmagnesium on the vacuum line and was then stored in ampules. ${ }^{1} \mathrm{H}$ NMR (400 $\left.\mathrm{MHz} \mathrm{CDCl}_{3}\right) \delta: 7.27$ (d, 1H, ArH), $7.2(\mathrm{~s}, 1 \mathrm{H}, \mathrm{ArH}), 7.05(\mathrm{~d}, 1 \mathrm{H}$, $\mathrm{ArH}), 6.73(\mathrm{dd}, 1 \mathrm{H}, \mathrm{CH}), 5.7\left(\mathrm{~d}, 1 \mathrm{H}, \mathrm{CH}_{2}\right), 5.2\left(\mathrm{~d}, 1 \mathrm{H}, \mathrm{CH}_{2}\right), 3.22$ (s, $4 \mathrm{H}, \mathrm{CH}_{2}$ ) (Figure 2i). ${ }^{13} \mathrm{C}$ NMR $\left(100 \mathrm{MHz}, \mathrm{CDCl}_{3}\right) \delta: 145.89$, $145.56,137.74,136.45,125.56,122.42,119.70,112.22,29.35$, and 29.19.

Anionic Polymerization of 4-Vinylbenzocyclobutene. Poly(4vinylbenzocyclobutene) (PVBCB) homopolymers were synthesized in benzene using standard all-glass high-vacuum techniques. ${ }^{35-37}$ The polymerization was performed in a reactor shown in Figure 1.
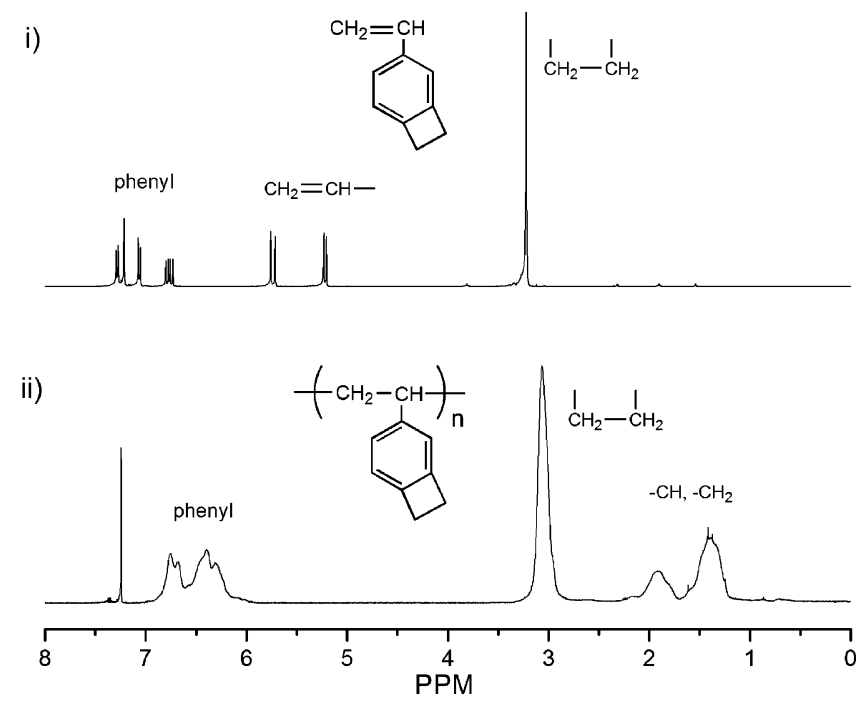

Figure 2. ${ }^{1} \mathrm{H}$ NMR spectra of 4-vinylbenzocyclobutene (i) and poly(4-vinylbenzocyclobutene) (ii) obtained using anionic polymerization.

The reactor was connected to a purge section containing a $250 \mathrm{~mL}$ flask with a septum inlet. The ampules containing initiator, monomer, and methonal were connected to the reactor, and the entire reactor was evacuated to attain high vacuum. Then, a small amount of $n$-BuLi (1.6 M in hexane, $5 \mathrm{~mL}$ ) was added into the reactor under static vacuum through a septum using a syringe, and the septum portion was removed by sealing the glass constriction, which was thoroughly washed by distilling hexane above the portion of the constriction using a wet liquid nitrogen towel. The hexane solution of $n$-BuLi was frozen and degassed thoroughly under high vacuum. $100 \mathrm{~mL}$ of benzene was distilled into the purge flask under high vacuum, and the entire reactor was sealed off from the vacuum line. The benzene containing $n$-BuLi was rinsed through out the reactor to quench any impurity present on the glass surface. The inner walls of the reactor were washed thoroughly by condensing pure benzene. Then, the reactor was positioned in a way that the pure benzene can be distilled into the reactor. The purge section containing the washed $n$-BuLi was removed from the reactor through heat-sealing of the glass constriction. Subsequently, the break-seals of the ampules containing 4-VBCB (3.0 g, $0.023 \mathrm{~mol})$ and $s$-BuLi $(0.055 \mathrm{M}$ in hexane, $2 \mathrm{~mL}, 0.00011 \mathrm{~mol})$ were opened and mixed with benzene. Immediately, an orange color developed, indicating the formation of propagating anion of 4-VBCB. The polymerization was allowed to proceed for $15 \mathrm{~h}$ at $25^{\circ} \mathrm{C}$ and terminated with methanol $(\sim 0.5 \mathrm{~mL})$ under vacuum. The reactor was opened, and the polymer was recovered by precipitation in excess methanol. The poly(4-vinylbenzocylcobutene) was dried under vacuum at $40{ }^{\circ} \mathrm{C}$ for $24 \mathrm{~h}$. The yield is $95 \%(2.85 \mathrm{~g}) .{ }^{1} \mathrm{H}$ NMR (400 MHz, $\mathrm{CDCl}_{3}$ ) $\delta:$ 6.2-6.9 (ArH), 3.22 (s, cyclobutene, $\left.\mathrm{CH}_{2}\right), 1.6-2.2(-\mathrm{CH}-), 1.2-1.58\left(-\mathrm{CH}_{2}\right)$ (Figure 2ii). $M_{\mathrm{n}, \mathrm{SEC}}=$ $27000 \mathrm{~g} / \mathrm{mol}, M_{\mathrm{w}} / M_{\mathrm{n}}=1.02$.

In the case of kinetics measurement, the ampules containing $4-\mathrm{VBCB}$ and decane were first opened and mixed with benzene. A small amount of monomer-decane solution $(\sim 3: 1 \mathrm{v} / \mathrm{v})$ was taken into ampules and sealed off for measurement of zero time monomer concentration. Subsequently, the initiator ampule was opened, and the progress of the reaction was followed by taking a small aliquot under vacuum at different times. The samples were analyzed for monomer conversion and molecular weight. The monomer conversion was monitored by gas chromatography using decane as internal standard.

Anionic Block Copolymerization of 4-Vinylbenzocyclobutene with Butadiene. The sequential block copolymerization was performed in a similar way as described above with a reactor containing an additional 1,3-butadiene ampule. In a typical reaction, $s$-BuLi $(1 \mathrm{~mL}, 0.001 \mathrm{~mol})$ and 4-VBCB (2 g, $0.015 \mathrm{~mol})$ were mixed in benzene $(100 \mathrm{~mL})$ at $30{ }^{\circ} \mathrm{C}$ and kept for $12 \mathrm{~h}$. A small amount of sample was with drawn in to an empty ampule and sealed 
Table 1. Anionic Polymerization of 4-Vinylbenzocyclobutene (4-VBCB) and Block Copolymerization with 1,3-Butadiene in Benzene at Room Temperature

\begin{tabular}{|c|c|c|c|c|c|c|c|c|}
\hline run & $\begin{array}{c}{[s-\mathrm{BuLi}] \times 10^{3}} \\
(\mathrm{~mol} / \mathrm{L})\end{array}$ & $\begin{array}{c}{[\mathrm{M}]_{1}{ }^{a}} \\
(\mathrm{~mol} / \mathrm{L})\end{array}$ & $\begin{array}{l}M_{\mathrm{n}, \mathrm{th}^{b}} \times 10^{-3} \\
(\mathrm{~mol} / \mathrm{g})\end{array}$ & $\begin{array}{c}{[\mathrm{M}]_{2}{ }^{c}} \\
(\mathrm{~mol} / \mathrm{L})\end{array}$ & $\begin{array}{c}M_{\mathrm{n} . \mathrm{SEC}}{ }^{d} \times 10^{-3} \\
(\mathrm{~mol} / \mathrm{g})\end{array}$ & $\begin{array}{c}M_{\mathrm{w}, \mathrm{LS}}^{e} \times 10^{-3} \\
(\mathrm{~mol} / \mathrm{g})\end{array}$ & $M_{\mathrm{w}} / M_{\mathrm{n}}$ & $T_{\mathrm{g}}^{f}\left({ }^{\circ} \mathrm{C}\right)$ \\
\hline 1 & 1.10 & 0.23 & 27.0 & & 27.0 & 30.0 & 1.02 & 120 \\
\hline 2 & 1.30 & 0.15 & 15.0 & & 16.0 & 17.0 & 1.02 & 119 \\
\hline 4 & 0.69 & 0.30 & 58.0 & & 53.0 & 60.0 & 1.03 & 121 \\
\hline 3 & 10.00 & 0.15 & 2.0 & 1.10 & 13.0 & 9.0 & 1.06 & \\
\hline $5^{g}$ & 1.75 & 0.27 & 20.0 & 0.65 & 83.0 & 55.0 & $1.08^{h}$ & \\
\hline
\end{tabular}

${ }^{a}$ Concentration of 4-VBCB. ${ }^{b} M_{\mathrm{n}, \mathrm{th}}=$ gram of $M_{1} /\left[s\right.$-BuLi]. ${ }^{c}$ Concentration of 1,3-butadiene. ${ }^{d}$ Number-average molecular weight $\left(M_{\mathrm{n}}\right)$ from size exclusion chromatography (SEC) calibrated with standard polystyrene. ${ }^{e}$ Weight-average molecular weight $\left(M_{\mathrm{w}}\right)$ determined using SEC-LS. ${ }^{f}$ Glass transition temperature, $T_{\mathrm{g}}$, was measured using a differential scanning calorimeter. ${ }^{g}$ Reaction performed in the presence of a small amount of tetrahydrofuran. ${ }^{h}$ After the fractionation.

off after washing the glass constriction with benzene from the reaction. Subsequently, $8 \mathrm{~mL}$ of 1,3 -butadiene $(6 \mathrm{~g}$ in $15 \mathrm{~mL}$ hexane) was added through a break-seal into the reactor containing living poly(4-vinylbenzocyclobutene) anions. Upon mixing of 1,3butadiene, the orange color of the reaction medium become colorless which indicated the initiation of 1,3-butadiene. The polymerization was kept for another $15 \mathrm{~h}$ at $25^{\circ} \mathrm{C}$ and terminated with methanol ( $\sim 0.5 \mathrm{~mL}$ ) under vacuum. The reactor was opened, and the block copolymer, poly(4-vinylbenzocyclobutene-block-butadiene), was precipitated in methanol and dried under vacuum at $40{ }^{\circ} \mathrm{C}$ for 24 h. The yield was $98 \%(\sim 7.8 \mathrm{~g}) .{ }^{1} \mathrm{H}$ NMR $\left(400 \mathrm{MHz}, \mathrm{CDCl}_{3}\right) \delta$ : 6.2-6.9 (ArH), $5.4(-\mathrm{CH}=\mathrm{CH}-), 4.8\left(-\mathrm{CH}=\mathrm{CH}_{2}\right), 3.22$ (cyclobutene, $\left.\mathrm{CH}_{2}\right), 2.1\left(-\mathrm{CH}_{2}-\right)(1.6-2.2(-\mathrm{CH}-), 1.2-1.58$ $\left(-\mathrm{CH}_{2}\right) \cdot M_{\mathrm{n}, \mathrm{SEC}}=3000 \mathrm{~g} / \mathrm{mol}, M_{\mathrm{w}} / M_{\mathrm{n}}=1.04$ (homopolymer) and $M_{\mathrm{n}, \mathrm{SEC}}=13000 \mathrm{~g} / \mathrm{mol}, M_{\mathrm{w}} / M_{\mathrm{n}}=1.06$ (diblock copolymer).

Characterization. Size exclusion chromatography (SEC) was used to determine molecular weights and molecular weight distributions $\left(M_{\mathrm{w}} / M_{\mathrm{n}}\right)$ of the polymer samples with respect to polystyrene standards (PSS, Germany). The unit was equipped with an isocratic pump (Knauer K-501), UV detector (Knauer UV-K2501), and RI detector (Knauer RI-K2301). Polymer samples were analyzed using Polymer Standard Service $1 \times 100 \AA$ and $1 \times$ linear SDV $5 \mu \mathrm{m}$ gel columns $(60 \mathrm{~cm})$ set or with Polymer Laboratories $2 \times$ mixed-B SDV gel columns $(30 \mathrm{~cm})$. THF was used as the mobile phase at a flow rate of $1 \mathrm{~mL} \mathrm{~min}{ }^{-1}$ at $30{ }^{\circ} \mathrm{C}$. PSS WinGPC software was used to acquire and analyze the chromatograms. In some cases, SEC was performed on a SEC-LS system consisting of a RI detector (Polymer Laboratories), light scattering $15^{\circ}$ and $90^{\circ}$ (Precision Detectors, $\lambda=685 \mathrm{~nm}, 30 \mathrm{~mW}$ ), and viscosity (Viscotek) detectors. The refractive index increment, $\mathrm{d} n / \mathrm{d} c$, of poly(4-vinylbenzocyclobutene) was measured using a Wyatt Technology OptiLab laser refractometer $(\lambda=690 \mathrm{~nm})$ in THF, and the average value was $0.196 \mathrm{~mL} / \mathrm{g}$. Monomer conversion was measured using decane as an internal standard in a HP gas chromatograph (GC) equipped with FID detector $\left(140{ }^{\circ} \mathrm{C}\right)$ and a BP1 (nonpolar) column at oven temperature $90{ }^{\circ} \mathrm{C}$ (ramp rate $\left.10{ }^{\circ} \mathrm{C} / \mathrm{min}\right)$. UV-vis spectra were recorded using a Thermo Spectronic's Biomate 5 instrument. ${ }^{1} \mathrm{H}$ NMR (400 MHz) and ${ }^{13} \mathrm{C}$ NMR (100 MHz) spectra were recorded on a Bruker AC-400 spectrometer. Thermogravimetric analysis was performed using a TA Instruments TGA Q50 analyzer in air and in $\mathrm{N}_{2}$ at $10^{\circ} \mathrm{C} / \mathrm{min}$. The glass transition temperature $\left(T_{\mathrm{g}}\right)$ of the polymers was determined by differential scanning calorimeter (DSC) using a TA Instruments DSC Q1000 at a heating rate of 10 ${ }^{\circ} \mathrm{C} / \mathrm{min}$. The samples were heated to $150{ }^{\circ} \mathrm{C}$ in order to keep the benzocyclobutene moiety intact for the determination of $T_{\mathrm{g}}$.

\section{Results and Discussion}

The synthesis of monomer (4-VBCB) was accomplished through the Wittig coupling reaction of 4-carboxaldehydebenzocyclobutene and methyltriphenylphosphonium ylide in THF as reported by Hawker and co-workers. ${ }^{30}$ 4-Carboxaldehydebenzocyclobutene was synthesized via the Grignard reagent of 4-bromobenzocyclobutene followed by reaction with $\mathrm{N}, \mathrm{N}$ dimethylformamide (Scheme 1). ${ }^{1} \mathrm{H}$ NMR and ${ }^{13} \mathrm{C}$ NMR spectroscopy of the distilled product supported the formation of 4-VBCB and showed characteristic signals corresponding to
Scheme 1. Synthesis of 4-Vinylbenzocyclobutene and Polymerization Using $s$-BuLi as Initiator

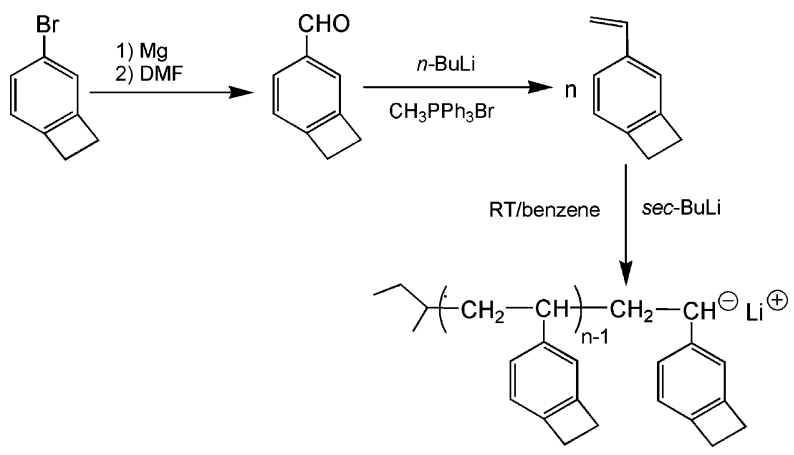

vinylic, aromatic, and cyclobutene protons at 5.20-5.80, 6.607.40, and $3.20 \mathrm{ppm}$, respectively (Figure $2 \mathrm{i}$ ).

Before performing the polymerization, 4-VBCB was distilled further from $\mathrm{CaH}_{2}$ and dibutylmagnesium into graduated ampules with break-seals, which were sealed off. Anionic polymerization was performed in benzene using $s$-BuLi as initiator under high vacuum using all glass break-seal techniques (Scheme 1). The results of the polymerization are given in Table 1. The polymerizations were conducted for $12 \mathrm{~h}$ at room temperature and terminated using a small amount of distilled/ degassed methanol. The precipitated polymers had molecular weights close to those theoretically calculated based upon the feed ratio of the monomer to the initiator.

The ${ }^{1} \mathrm{H}$ NMR spectrum of the polymer revealed the absence of vinyl protons and the presence of protons corresponding to the backbone and benzocyclobutene side groups (Figure 2ii). The poly(4-vinylbenzocyclobutene) (poly(4-VBCB)) exhibits a narrow molecular weight distribution $\left(M_{\mathrm{w}} / M_{\mathrm{n}} \leqslant 1.03\right)$ with very high initiator efficiency $(f=1)$. Although the molecular weights were calculated using SEC calibrated with standard polystyrene, the molecular weights obtained for the poly(4-VBCB) samples were only slightly higher than those theoretically calculated, indicating that the cyclobutene does not have a major influence on the hydrodynamic volume of the polymer chain. This was confirmed from the results of the molecular weight determination using a SEC coupled with two angles laser light scattering, which showed that the poly(4-VBCB)s have predictable molecular weights (Table 1).

To confirm the living nature of the polymerization, kinetic studies of 4-VBCB were also performed at an initial initiator concentration of $[\mathrm{I}]_{0}=7.7 \times 10^{-4} \mathrm{~mol} / \mathrm{L}$ under vacuum. After mixing the initiator with monomer, the reaction mixture was collected in a $250 \mathrm{~mL}$ round-bottom flash of the reactor (Figure 1), equipped with a UV-vis cell and several empty ampules for taking aliquots. A small amount of sample $(4-5 \mathrm{~mL})$ was transferred into the UV-vis cell and was sealed off for UV measurement. Samples were taken at regular intervals for GC and SEC analysis to determine the monomer conversion and molecular weight characterization, respectively. 


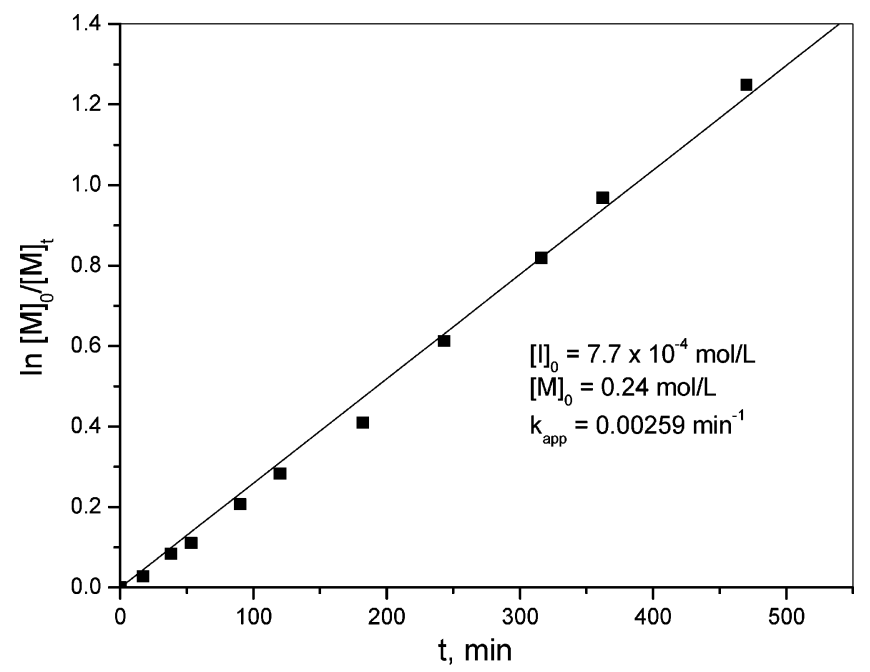

Figure 3. First-order time-conversion plot of anionic polymerization of 4-vinylbenzocyclobutene using $s$-BuLi as initiator in benzene at 25 ${ }^{\circ} \mathrm{C}$.

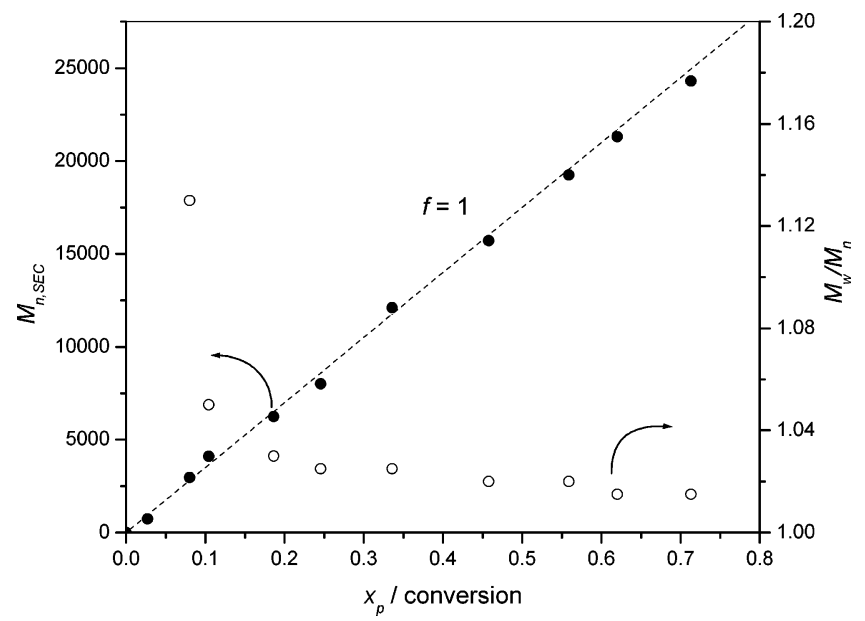

Figure 4. Molecular weight and molecular weight distribution of poly(4-vinylbenzocyclobutene) during the polymerization in benzene at 25 ${ }^{\circ} \mathrm{C}$.

A linear first-order semilogarithmic time-conversion plot was obtained, $\ln [\mathrm{M}]_{0} /[\mathrm{M}]_{t}=k_{\text {app }} t$, which indicates the absence of termination reactions during the polymerization of $4-\mathrm{VBCB}$ at room temperature in benzene (Figure 3 ). The apparent rate constant $k_{\mathrm{app}}$ is given by the equation $k_{\mathrm{app}}=k_{\mathrm{p}}[\mathrm{P} *]$, in which $k_{\mathrm{p}}$ is the propagation rate constant and [P*] the active center concentration, equal to initiator concentration, since the initiator efficiency is close to one for this polymerization (Table 1, Figure 4). The molecular weight dependence of the growing polymer with respect to the conversion $\left(x_{\mathrm{p}}\right)$ is linear (Figure 4$)$. The points lie on the theoretical line, again indicating that the polymerization process is free from transfer reactions. The molecular weight of the poly(4-VBCB) during the course of the polymerization gradually increased with conversion, as expected for a living system (Figure 5). The poly(4-VBCB)s obtained in the batch and in the kinetic experiments all exhibited narrow molecular weight distributions (Figure 4). The $T_{\mathrm{g}}$ of poly(4VBCB)s is $\sim 120^{\circ} \mathrm{C}$, which is slightly higher than polystyrene.

The results confirm that the anionic polymerization of 4-vinylbenzocyclobutene proceeds in a living manner without termination or transfer reactions. The presence of the benzocyclobutene groups does not interfere with the propagating anions in benzene at room temperature. However, the color of the propagating anion is a slightly more intense orange than

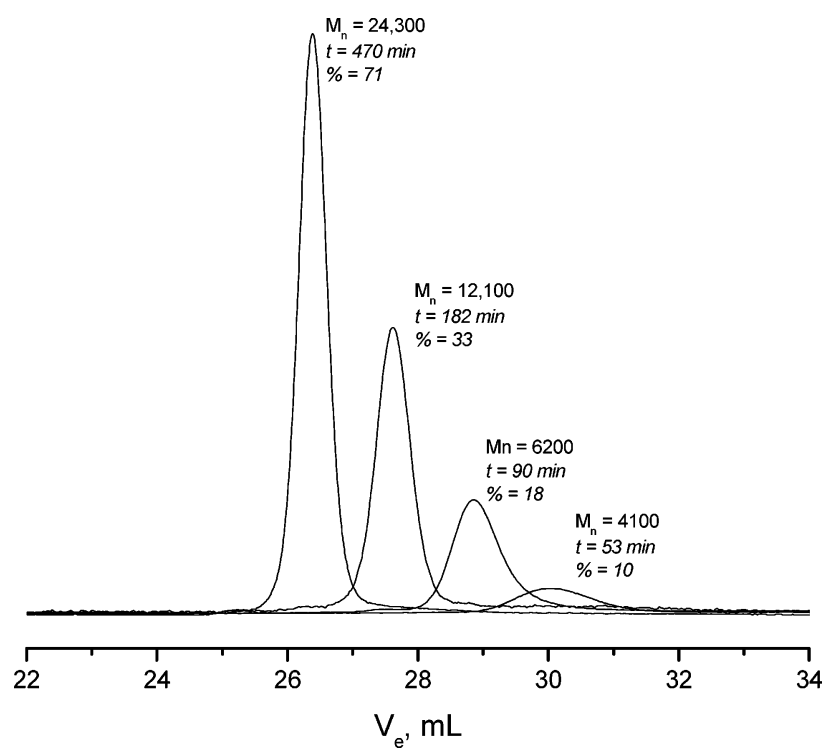

Figure 5. Size exclusion chromatography eluograms of poly(4vinylbenzocyclobutene) taken during the course of anionic polymerization in benzene at $25{ }^{\circ} \mathrm{C}$. $M_{\mathrm{n}}=$ number-average molecular weight with respect to polystyrene standard, $t=$ polymerization time, and $\%$ $=$ percentage of monomer conversion.

that of an unsubstituted styryl anion due to the presence of the cycloalkyl group. The UV-vis spectrum of the living polymerization medium revealed two absorbance bands at 330 and $465 \mathrm{~nm}$, the intensity of which did not change over $12 \mathrm{~h}$. This suggests that the concentration of propagating species remains constant throughout the polymerization. In a couple of batch experiments, a small amount of THF vapors were codistilled into the reactor along with benzene. The color of the reaction medium in these reactions was distinctly red, indicating a solvation-induced delocalization of the propagating anions. The $\mathrm{UV}-$ vis bands at $\sim 330$ and $\sim 465 \mathrm{~nm}$, corresponding to the propagating species in the presence of a small amount of THF, did not remain constant. After the complete conversion of monomer, the absorbance bands had gradually diminished, thereby confirming that the propagating $4-\mathrm{VBCB}$ anion is not stable in the presence of a small amount of THF at $25^{\circ} \mathrm{C}$.

Block Copolymer Formation with 1,3-Butadiene. The living nature of the polymerization was examined using a sequential block copolymerization with 1,3-butadiene. After a complete conversion of 4-vinylbenzocyclobutene, a small amount of the sample was withdrawn for characterization and a known amount of 1,3-butadiene was added to resume the polymerization. The orange color of the reaction mixture turned colorless immediately after the addition of 1,3-butadiene. The reaction was allowed to proceed for another $12 \mathrm{~h}$ at room temperature before termination with a small amount of methanol. The block copolymer was precipitated in excess methanol and dried. The poly(4-vinylbenzocyclobutene- $b$-butadiene) exhibited a narrow molecular weight distribution without the presence of homopolymer (Figure 6). However, the block copolymerization in the presence of THF did not give pure diblock copolymer. The diblock copolymer contained a large amount of homopolymer, indicating the self-termination of chain ends in the presence of THF at $25^{\circ} \mathrm{C}$ (Figure 7).

Thermal Properties of Poly(4-vinylbenzocyclobutene). The benzocyclobutene moiety undergoes thermal ring opening to generate diradicals. ${ }^{30,31}$ Evidence of thermal cross-linking of poly(4-VBCB) was seen by thermogravimetric analysis (TGA) under air. The derivative weight loss with respect to temperature shows two distinct steps of decomposition. The first decomposi- 

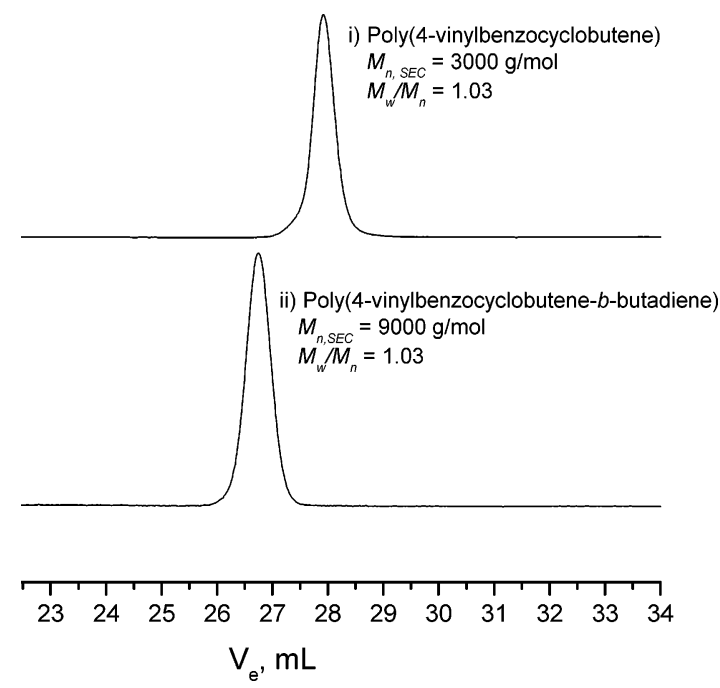

Figure 6. Size exclusion chromatography eluograms of diblock copolymerization of 4-vinylbenzocyclobutene with 1,3-butadiene in benzene at $25^{\circ} \mathrm{C}$ : (i) homopolymer, poly(4-vinylbenzocyclobutene), and (ii) after butadiene addition, poly(4-vinylbenzocyclobutene- $b$ butadiene).

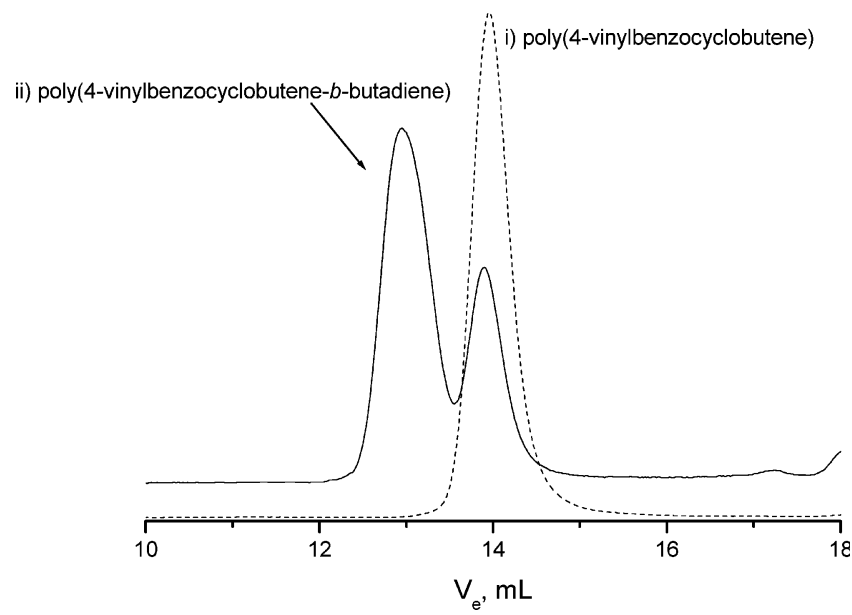

Figure 7. Size exclusion chromatography eluograms of diblock copolymerization of 4-vinylbenzocyclobutene with 1,3-butadiene in benzene in the presence of a small amount of tetrahydrofuran at 25 ${ }^{\circ} \mathrm{C}$ : (i) before and (ii) after the addition of 1,3-butadiene.

tion was observed at $360-480{ }^{\circ} \mathrm{C}\left(T_{\max }-455^{\circ} \mathrm{C}\right)$ and the second at a higher temperature $\left(T_{\max }-566^{\circ} \mathrm{C}\right)$. The major weight loss at $455^{\circ} \mathrm{C}$ is a result of thermal decomposition of the polymer. At $200-240{ }^{\circ} \mathrm{C}$, the cyclobutene moiety undergoes inter- or intramolecular cross-linking in the solid state, leading to the formation of a rigid network structure which requires higher temperature for decomposition. The second decomposition was attributed to the cross-linked material of the poly(4VBCB) (Figure 8). At $150{ }^{\circ} \mathrm{C}$, weight increases (maximum at $\sim 320{ }^{\circ} \mathrm{C}$ ) depending on the molecular weight of the homopolymer and the heating rate $\left({ }^{\circ} \mathrm{C} / \mathrm{min}\right)$ when the TGA experiments were conducted in air. This weight increase is attributed to the formation of radicals from the cyclobutene moieties and their reaction with oxygen present in the furnace while undergoing cross-linking. The formed radicals undergo rapid reaction with the oxygen and form $-\mathrm{C}-\mathrm{O}-$ linkages, leading to a slight weight gain at $\sim 150{ }^{\circ} \mathrm{C}$ before the decomposition. When the TGA experiments were performed under $\mathrm{N}_{2}$, such an increase was not observed, and the homopolymer underwent decomposition in a single step. A detailed study of the kinetics of thermal

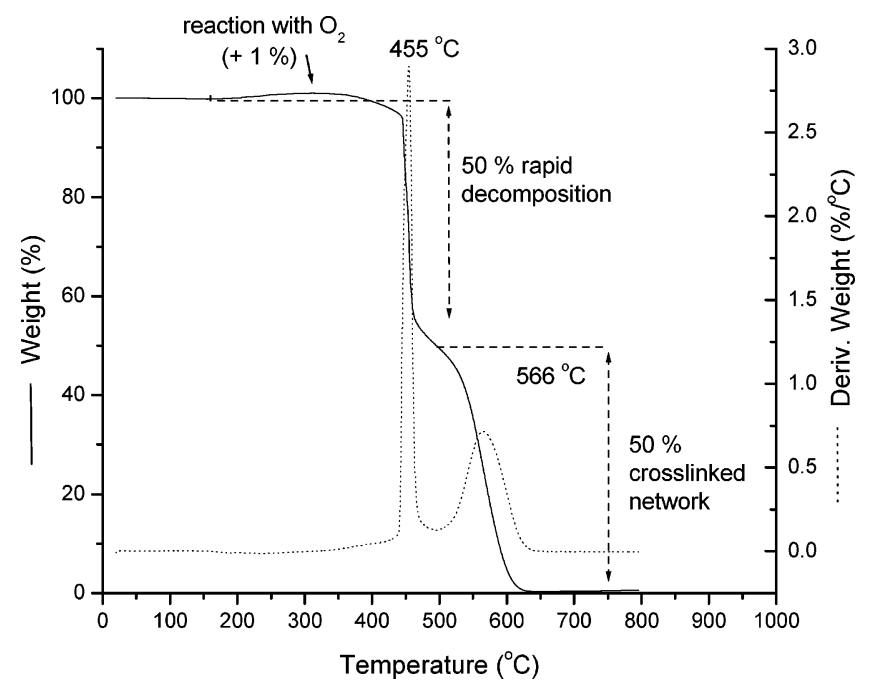

Figure 8. Thermogravimetric analysis of poly(4-vinylbenzocyclobutene) in air at a heating rate of $10{ }^{\circ} \mathrm{C} / \mathrm{min}$, reflecting weight gain, decomposition, and cross-linking reactions.

decomposition of poly(4-VBCB) is currently underway in our laboratory.

\section{Conclusions}

Living anionic polymerization of 4-vinylbenzocyclobutene was performed in benzene using $s$-BuLi as initiator. The polymerization proceeds without termination or transfer reactions. SEC results show that PVBCB can be synthesized with predetermined molecular weights and narrow molecular weight distributions. A well-defined block copolymer with butadiene was prepared and characterized. Thermal cross-linking of pendent benzocylcobutene groups was detected in thermogravimetric analysis, resulting in multistep decomposition.

Acknowledgment. Research was sponsored by the Division of Materials Sciences and Engineering, Office of Basic Energy Sciences, U.S. Department of Energy, under Contract DE-AC0500OR22725 with Oak Ridge National Laboratory, managed and operated by UT-Battelle, LLC. We thank the Dow Chemical Company for a generous supply of 4-bromobenzocyclobutene. The work at NCL was supported by D.B.'s start-up grant (MLP 007926-NCL).

\section{References and Notes}

(1) Szwarc, M. Carbanions Living Polymers and Electron-Transfer Process; Wiley-Interscience: New York, 1968.

(2) Young, R. N.; Quirk, R. P.; Fetters, L. J. Adv. Polym. Sci. 1984, 56, $1-90$.

(3) Hirao, A.; Nagahama, H.; Ishizone, T.; Nakahama, S. Macromolecules 1993, 26, 2145-2150.

(4) Avgeropoulos, A.; Hadjichristidis, N. J. Polym. Sci., Polym. Chem. Ed. 1997, 35, 813-816.

(5) Fontanille, M. In Comprehensive Polymer Science; Allen, G., Bevington, J. C., Eds.; Pergamon: Oxford, 1988; Vol. 3, p 425.

(6) Bi, L.-K.; Fetters, L. J. Macromolecules 1976, 9, 732-742.

(7) Hirao, A.; Hattori, I.; Sasagawa, T.; Yamaguchi, K.; Nakahama, S. Makromol. Chem. 1982, RC3, 59-63.

(8) Uhrig, D.; Mays, J. W. Macromolecules 2002, 35, 7182-7190.

(9) Pitsikalis, M.; Pispas, S.; Mays, J. W.; Hadjichristidis, N. Adv. Polym. Sci. 1998, 135, 1-137.

(10) Beyer, F. L.; Gido, S. P.; Poulos, Y.; Avgeropoulos, A.; Hadjichristidis, N. Macromolecules 1997, 30, 2373-2376.

(11) Allgaier, J.; Young, R. N.; Efstratiadis, V.; Hadjichristidis, N. Macromolecules 1996, 29, 1794-1797.

(12) Floudas, G.; Pispas, S.; Hadjichristidis, N.; Pakula, T.; Erukhimovich, I. Macromolecules 1996, 29, 4142-4154.

(13) Schappacher, M.; Deffieux, A. Macromolecules 2005, 38, 7209-7213. 
(14) Bates, F. S.; Frederickson, G. H. Annu. Rev. Phys. Chem. 1990, 41, 525-557.

(15) Yan, X.; Liu, G.; Li, Z. J. Am. Chem. Soc. 2004, 126, 10059-10066.

(16) Yan, X.; Liu, F.; Li, Z.; Liu, G. Macromolecules 2001, 34, $9112-$ 9116.

(17) Liu, G.; Qiao, L.; Guo, A. Macromolecules 1996, 29, 5508-5510.

(18) Drockenmuller, E.; Li, L. Y. T.; Ryu, D. Y.; Harth, E.; Russell, T. P. Kim, H.-C.; Hawker, C. J. J. Polym. Sci., Part A: Polym. Chem. 2005 , 43, 1028-1037.

(19) Hirao, A.; Loykulnant, S.; Ishizone, T. Prog. Polym. Sci. 2002, 27, 1399-1471.

(20) Ruckenstein, E.; Zhang, H. Macromolecules 1999, 32, 6082-6087

(21) Hirao, A.; Nakahama, S. Prog. Polym. Sci. 1992, 17, 283-317.

(22) Hirao, A.; Hatayama, T.; Nagawa, T.; Yamaguchi, M.; Yamaguchi, K.; Nakahawa, S. Macromolecules 1987, 20, 242-247.

(23) Yamaguchi, K.; Hirao, A.; Suzuki, K.; Takenaka, K.; Nakahama, S.; Yamazaki, N. J. Polym. Sci., Polym. Lett. Ed. 1983, 21, 395-401.

(24) Hsieh, H. L.; Quirk, R. P. Anionic Polymerization: Principles and Practical Applications; Marcel Dekker: New York, 1996.

(25) Wong, P. K. In US Patent 4,698,394, Shell Oil Company, Houston, TX, 1987.

(26) Wong, P. K. In US Patent 4,722,974, Shell Oil Company, Houston, TX, 1988.

(27) Endo, T.; Koizumi, T.; Takata, T.; Chino, K. J. Polym. Sci., Part A: Polym. Chem. 1995, 33, 707-715.
(28) Chino, K.; Endo, T. J. Polym. Sci., Part A: Polym. Chem. 2000, 38, 3434-3439.

(29) Chino, K.; Takata, T.; Endo, T. J. Polym. Sci., Part A: Polym. Chem. 1999, 37, 59-67.

(30) Harth, E.; Horn, B. H.; Lee, V. Y.; Germack, D. S.; Gonzales, C. P.; Miller, R. D.; Hawker, C. J. J. Am. Chem. Soc. 2002, 124, 86538660.

(31) Deeter, G. A.; Venkataraman, D.; Kampf, J. W.; Moore, J. S. Macromolecules 1994, 27, 2647-2657.

(32) Blomberg, S.; Ostberg, S.; Harth, E.; Bosman, A. W.; Horn, B.; Hawker, C. J. J. Polym. Sci., Part A: Polym. Chem. 2002, 40, 13091320.

(33) Herati, S. R.; Herati, S. R. J. Polym. Sci., Part A: Polym. Chem. 2004, 42, 1934-1938.

(34) Hawker, C. J.; Wooley, K. L. Science 2005, 309, 1200-1205.

(35) Hadjichristidis, N.; Iatrou, H.; Pispas, S.; Pitsikalis, M. J. Polym. Sci. Part A: Polym. Chem. 2000, 38, 3211-3234.

(36) Morton, M.; Fetters, L. J. Rubber Chem. Technol. 1975, 48, 359409.

(37) Uhrig, D.; Mays, J. W. J. Polym. Sci., Part A: Polym. Chem. 2005, $43,6179-6222$

MA060175E 